Revista de Negócios_ISSN 1980.4431_vol. 19, n. 2, p. 86_108, 2014_DOI:10.7867/1980431.2014v19n2p86_108

\title{
Empreendedorismo inovador gerado pelas incubadoras de base tecnológica: Mapeamento da produção científica até 2013
}

\section{The inovator entrepreneurship generated by technology incubators: Mapping of scientific production until 2013}

\author{
Cristina Martins \\ Unisul Universidade do Sul de Santa Catarina - Brasil \\ crismartins2611@gmail.com \\ Gabriela Gonçalves Silveira Fiates \\ UFSC Universidade Federal de Santa Catarina - Brasil \\ ggsf_70@hotmail.com \\ Ademar Dutra \\ Unisul Universidade do Sul de Santa Catarina - Brasil \\ ademarunisul@gmail.com \\ André Luís da Silva Leite \\ UFFS Universidade Federal da Fronteira Sul - Brasil \\ andre.leite@live.com \\ Pollyanna Gerola Giarola \\ Unisul Universidade do Sul de Santa Catarina - Brasil \\ pollygerola@gmail.com
}

Recebido em 28 de março de 2012. Alterado em 10 de abril de 2014. Aprovado em 10 de junho de 2014

Editor Responsável: Edson Roberto Scharf, Dr.

Processo de avaliação por double blind review

\section{Resumo}

Atualmente, o empreendedorismo e a inovação passaram a ser considerados fatores fundamentais na busca pela competitividade das organizações, sobretudo nos setores em que a tecnologia é elemento determinante para a vantagem competitiva. A presente pesquisa tem como objetivo investigar a produção científica sobre o empreendedorismo inovador gerado pelas incubadoras de base tecnológica até o exercício de 2013. Trata-se de um estudo bibliométrico, de natureza descritiva, com abordagem quantitativa a partir de uma pesquisa bibliográfica. Foram analisados como amostra final 380 trabalhos, originários da base de periódicos Ebsco, anais dos eventos Anpad e Anprotec, além de teses e dissertações dos bancos da Capes e Domínio
\end{abstract}

Público. Como resultados destacam-se: (i) o número máximo de publicações por autor, sobre o tema empreendedorismo inovador, foi de cinco artigos; (ii) o número máximo de dissertações e teses orientadas, sobre o tema, foi de quatro trabalhos por orientador; (iii) as maiores facilidades de acesso a informação estão para indivíduos que realizam conexões entre diferentes redes, tendo como melhor capital social os autores Gabriela Gonçalves Silveira Fiates e Afonso Augusto Teixeira de Freitas de Carvalho Lima; (iv) o crescimento significativo das publicações, a partir de 1998, destacando-se os anos de 2005 e 2006, que atingiram ambos $10,26 \%$ do total da amostra; (v) os eventos promovidos pela Anpad que mais publicaram anais foram o Enanpad e o Simpósio de Gestão da Inovação Tecnológica, com maior 
incidência sobre os temas Empreendedorismo e Inovação, seguido de Estratégias, Empreendedorismo e Desenvolvimento (incubadoras, polos e parques tecnológicos).

Palavras-Chave: Empreendedorismo inovador. Incubadoras de base tecnológica. Bibliometria.

\begin{abstract}
Nowadays, entrepreneurship and innovation can be considered key factors in the search for competitiveness of organizations, especially in industries in which technology is a decisive factor for competitive advantage. This article aims to investigate the scientific literature about entrepeneurship generated by technology-based incubators until the year 2013. This is a Bibliometric study with descriptive nature, with quantitative approach from a bibliografy research. Were taken as final sample 380 jobs, originating in Ebsco serials, based annals of Anpad events plus Anprotec, and theses and dissertations based at the CAPES databank. We concluded that: (i) the maximum number of publications by author, about the theme entrepeneurship were five articles; (ii) the maximum number of dissertations and theses, oriented on the topic, was four guiding work; (iii) the major means of access to information are for individuals who make connections between different networks, and how to better share capital the authors Gabriela Gonçalve Silveira Fiates and Afonso Augusto Teixeira de Freitas de Carvalho Lima; (iv) the significant increase of publications, from 1998, highlighting the years 2005 and 2006, reaching both $10.26 \%$ of the total sample; (v) the events promoted by the most published Annals of Anpad were the Enanpad Symposium and Management of Technological Innovation, focusing on Entrepreneurship and Innovation topics, followed by Strategy, Entrepreneurship and Development (incubators, technology parks and centers).
\end{abstract}

Keywords: Inovator entrepreneurship. Business Incubators. Bibliometry.

\section{Introdução}

Com a globalização e a crescente pressão sobre as organizações para adaptação contínua ao contexto e outros elementos que configuram a chamada nova competição, a inovação se coloca como um diferencial real para organizações, sobretudo para as micro e pequenas empresas (MPEs). Consideradas um dos pilares da economia brasileira, as MPEs representam 99\% das empresas e abarcam uma fatia considerável de $60 \%$ dos 94 milhões de empregos no país (BRASIL, 2012). Embora, representem apenas $20 \%$ de participação no Produto Interno Bruto (PIB), elas são potencializadoras de inovação tecnológica e de exportação, não se restringindo tão somente ao mercado local ou regional, mas lançando-se a concorrer também no mercado internacional (DOLABELA, 1999; BRASIL, 2012). Em contrapartida, além da informalidade representada por mais de dois milhões de micro e pequenas empresas de um total de cinco milhões e trezentos mil, a quantidade de MPEs que nascem sem condições de competição e não sobrevivem, ocasionando uma mortalidade substancial dos empreendimentos chega a $75 \%$ em até cinco anos, o que caracteriza uma das maiores vulnerabilidades do mercado brasileiro (CHALELA, 2008; FECOMÉRCIO, 2011; SARKAR, 2008).

Deste modo, é preciso reconhecer que as MPEs necessitam de uma atenção especial. E, para suprir essa atenção necessária, são utilizados vários sistemas e mecanismos que induzem a criação de empresas inovadoras. Geralmente por meio de Polos, Parques, Distritos Industriais, Escolas de Empreendedores, Centros de Inovação, entre outros mecanismos de indução e suporte (BRASIL, 2000; CHALELA, 2008; FECOMÉRCIO, 2011).

Dentre esses mecanismos e arranjos destacam-se as incubadoras de base tecnológica (IEBTs), que podem ser consideradas lócus natural para o surgimento do empreendedorismo inovador e para a provisão de suporte e incentivo à criação e desenvolvimento de micro e pequenas empresas, já que oferecem formação complementar ao empreendedor em seus aspectos técnicos e gerenciais, além do espaço físico necessário para este desenvolvimento. Em um contexto onde o conhecimento, a eficiência e a rapidez no processo de inovação passam a ser reconhecidamente 
os elementos decisivos para a competitividade das economias, o processo de incubação pode ser crucial para que a inovação se concretize em tempo hábil para suprir as demandas do mercado (BALDISSERA, 2001; BRASIL, 2000).

Frente ao exposto o presente artigo tem como objetivo investigar a produção científica sobre empreendedorismo inovador gerado pelas incubadoras de base tecnológica até $\mathrm{o}$ exercício de 2013.

Para consecução do objetivo geral, foram estabelecidos como objetivos específicos: (i) selecionar os artigos relacionados ao tema empreendedorismo inovador nas bases de dados especificadas; (ii) identificar as principais características da produção científica pesquisada, bem como proceder a tabulação e geração das frequências requeridas; e, (iii) analisar o conteúdo dos resultados encontrados a partir das produções científicas pesquisadas.

A identificação de publicações acerca do processo de empreendedorismo inovador em meios de divulgação científica contribui tanto no âmbito acadêmico como prático, pois sinaliza pontos fortes e fracos das experiências anteriores, verifica as características e vertentes dos estudos já publicados, bem como permite identificar as lacunas do estado da arte podendo contribuir com a proposição de uma agenda de pesquisa.

Além desta seção introdutória, este artigo contempla: seção 2 - referencial teórico; seção 3 - metodologia; seção 4resultados, seção 5 - considerações finais e por fim, as referências utilizadas.

\section{Referencial teórico}

Os eixos norteadores que informam o referencial teórico envolvem os temas empreendedorismo inovador, incubadoras de empresas e estudos bibliométricos anteriores.

\subsection{Empreendedorismo inovador}

Embora diversos autores tais como Cantillon (1755), Smith (1776), Say (1803) tenham buscado definir o empreendedorismo, foi Schumpeter (1934) que formalizou sua definição enfatizando sua relação com a inovação e a tecnologia. Sua clássica definição de que só é empreendedor aquele que inova (SCHUMPETER, 1934) já sinalizava a importância de considerar outros elementos e perspectivas que não somente a criação de empresas.

Neste sentido, Drucker (1986, p.25) afirma que "a inovação é o instrumento específico dos empreendedores, o meio pelo qual eles exploram a mudança como uma oportunidade para um negócio diferente ou um serviço diferente", sendo possível ser apresentado como uma disciplina, capaz de ser compreendida, aprendida e praticada.

Corroborando com o exposto, Rushing (1990) ressalta que a importância do estudo do empreendedorismo dá-se em função de sua contribuição à sociedade, além de estimular a inovação e o crescimento econômico. Desta forma, o empreendedorismo se configura quando a ideia de inovação é concebida, é viável e se constitui em uma competência única, formando um diferencial no meio em que se insere (SALAZAR et al., 2003).

Já Dornelas (2006) e Sarkar (2008) alegam que a definição de inovação remete ao mesmo que atualmente se entende por empreendedorismo, já que estão intrinsecamente associados. Desta forma, entende-se que todo empreendedorismo é inovador por sua essência e, portanto, passa a ser tanto percebido, como medido por meio da inovação, vindo a ser chamado também como "empreendedorismo inovador" (SARKAR, 2008), já que estão intimamente integrados e trabalhando em simbiose (FARBER; HOELTGEBAUM; KLEMZ， 2011; MARTINS， 2013; MARKATOU; STOURNARAS, 2013).

Frente à importância do fenômeno, também apontado desde a época de 
Schumpeter para prosperidade econômica (1934), diversos aspectos podem promover o empreendedorismo inovador (ALLEN; MCCLUSKEY, 1990). Aspectos internos às organizações como aponta Fiates e Fiates (2008), tais como: cultura organizacional; estrutura organizacional; pessoas e tecnologias. E, aspectos externos que podem solucionar problemas sociais, como emprego e renda. É neste sentido que a ANPROTEC $(2004$, p.7) ressalta projetos e iniciativas adotadas por muitos municípios no Brasil que estão obtendo sucesso no desenvolvendo de suas regiões consolidando como verdadeiras "alavancas" do empreendedorismo inovador, tais como as incubadoras de empresas.

\subsection{Incubadoras de empresas}

As incubadoras de empresas são ambientes dotados de capacidade técnica, gerencial, administrativa e infraestrutura para amparar o pequeno empreendedor. Elas disponibilizam espaço apropriado e condições efetivas para abrigar ideias inovadoras e transformá-las em empreendimentos de sucesso (ANPROTEC, 2006) além de oferecem um leque de serviços diferenciados, bem como um passaporte para o mercado exterior e contato com empresas âncoras e capitalistas interessados em investir em novas empresas (DORNELAS, 2006).

De forma complementar, Bridi (2004, p. 42) coloca que a finalidade das incubadoras "é viabilizar projetos, criando novos produtos, processos ou serviços, gerando novas empresas que, após deixarem a incubadora, estejam aptas a se manter no mercado". Assim, este mecanismo pode mitigar efeitos nocivos e maximizar a utilização dos recursos humanos, financeiros e materiais de que dispõem os micro e pequenos empresários, estimulando o empreendedorismo e divulgando as oportunidades de criação de por meio de soluções que estão se

negócios próprios com chances reais de êxito e buscas de empregos (BRASIL, 2000).

Todos estes benefícios fazem com que a taxa de mortalidade de empresas incubadas seja minimizada. Segundo dados da ANPROTEC (2004), a taxa média de sobrevivência das empresas geradas em incubadoras é de $82 \%$. Enquanto que no caso das micro e pequenas empresas, que não passaram pelo processo de incubação, apenas $40 \%$ sobrevivem mais de três anos no mercado.

Nesta perspectiva, Neck, Meyer, Cohen e Corbett (2004) acrescentam que a existência de incubadoras pode transformar uma região em um polo de empreendedorismo, pois incentiva negócios empreendedores. Ademais, as incubadoras geralmente abrigam negócios de mesma natureza ou natureza complementar, que com o tempo acabam se tornando um forte grupo naquele ramo de atividade, devido à sinergia criada (CHAN; LAU, 2005).

Desta forma, há diferentes tipos de incubadoras que desempenham diferentes papéis (AERNOUDT, 2004), todavia o foco deste trabalho recai sobre as incubadoras de base tecnológica.

\subsubsection{Incubadoras de base tecnológica (IEBTs)}

As incubadoras de base tecnológica abrigam empresas cujos produtos, processos ou serviços são gerados a partir de resultados de pesquisas aplicadas, nas quais a tecnologia representa alto valor agregado. Neste sentido, elas se distinguem das incubadoras de setores tradicionais, por abrigarem exclusivamente empreendimentos oriundos de pesquisa científica e, segundo Baêta (1999, p. 15) por possuírem características próprias, tais como:

a intensa relação entre $\mathrm{o}$ setor produtivo e a pesquisa acadêmica;

Revista de Negócios, ISSN 1980-4431, Blumenau, Brasil, v. 19, n. 2, p. 86-108, Abril/Junho de 2014. 
o uso compartilhado de espaços, equipamentos e serviços;

a informalidade das comunicações;

a participação dos vários parceiros em que se apoia o processo de inovação;

a aprendizagem interativa que se apresenta como aspecto importante no ambiente das IEBTs;

a capacidade de lidar com dilemas organizacionais próprios dessa estrutura de parceria e do processo de inovação e que aparece como um fator importante na busca de gerenciar relações entre opostos.

Segundo Baldissera (2001), além de uma alternativa viável e confiável, há uma tendência de as incubadoras de base tecnológica serem priorizadas, pois a modernização constante e veloz aponta para a necessidade de se atentar para o novo e para o emprego de tecnologias de ponta.

Adicionalmente, conforme informações levantadas pela Anprotec (2006), 70\% dos negócios no Brasil são gerados por empresas de base tecnológica. E em proporções muito maiores do que em 1986 como se pode observar no Gráfico 1, que demonstra a evolução das incubadoras em operação no país.

Gráfico 1: Evolução do movimento Brasileiro de incubadoras em operação - 2006

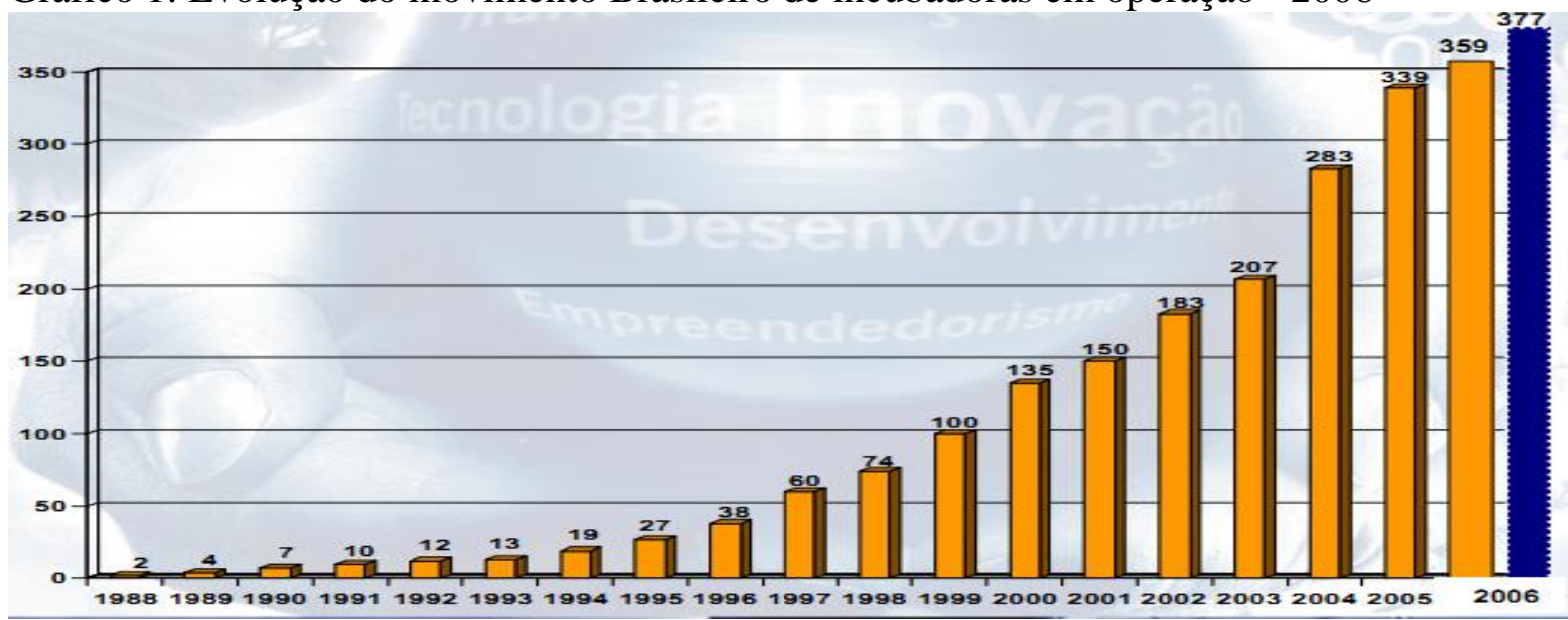

Fonte: Anprotec, 2006.

No Brasil, desde 1986 quando foi criada a primeira incubadora, até 1993 havia 16 incubadoras em atividade. Dessas, 50\% tinham menos de dois anos e somente três, haviam sido constituídas antes de 1990. Cinco dos empreendimentos na primeira safra não se consolidaram e nas demais, houve uma variação de um a 22 no número de empresas que se tornaram fortes e deixaram a incubadora para ter vida própria (BALDISSERA, 2001). Atualmente, as incubadoras brasileiras têm gerado aproximadamente 20.000 empregos diretos. Além disso, já foram consideradas aptas ao mercado (graduadas) cerca de 1.500 empresas, as quais faturam mais de $\mathrm{R} \$ 1,6$ bilhão por ano e geram cerca de 13.500 postos de trabalho (ANPROTEC, 2011).
Portanto, as incubadoras de empresas cada vez mais dinâmicas e em número maior são mecanismos de promoção do empreendedorismo inovador, contribuindo de maneira decisiva para o desenvolvimento das diferentes regiões do país, tanto por razões econômicas, quanto de natureza social.

Face ao exposto, torna-se importante compreender o status quo do tema aqui proposto e para tal, abordar-se-á o tópico 2.3.

\subsection{Estudos bibliométricos anteriores}

Com o intuito de averiguar as características e vertentes dos estudos bibliométricos já publicados acerca do empreendedorismo inovador, deparou-se 
com resultados isolados dos temas "empreendedorismo" e "inovação". Para melhor compreensão do status quo, apresenta-se uma síntese do escopo e frutos destas pesquisas.

Os artigos de Oliveira e Muylder (2007) e Muylder, Rocha, Gonçalves e Souza (2008) apontam o empreendedor como agente de grande importância, tanto pelo seu papel inovador como o de criador de empregos e riqueza. Os estudos, embasados em bibliometria realizados na base Enanpad 2007/2008, demonstram que a maior concentração de trabalhos sobre "empreendedorismo" encontra-se nas áreas de "Estratégia em Organizações" e "Gestão de Ciência, Tecnologia e Inovação", com presença de percentuais mínimos nas áreas de "Finanças" e "Gestão de Operações e Logística". Destaca-se ainda que Schumpeter é o autor mais citado dentre as pesquisas, apontado não somente por atrelar o empreendedorismo à inovação, mas também por salientar a importância de buscar novos produtos e mercados, a fim de promover o desenvolvimento socioeconômico.

Nesta linha, o estudo realizado por Borba, Hoeltgebaum e Silveira (2011) teve como objetivo analisar a produção científica do empreendedorismo apresentada no Academy of Management Meeting (AOM - Meeting), citado pelos autores como o maior evento internacional e um dos mais antigos em administração de empresas. Para tal, os autores coletaram dados referentes ao período de 1954 a 2005 na base de dados Ebsco (Business Source Premier). A resultância, como nos dois primeiros estudos, também enfatizou as obras de Joseph Alois Schumpeter; no entanto, outros pontos foram destaques: a projeção da inovação via o empreendedorismo; o declínio gradual do empreendedorismo sob a ótica da psicologia diante de trabalhos do empreendedorismo no escopo da administração de pequenos negócios e inovação.
No que diz respeito à inovação, o trabalho de Kneipp, Gomes, Rosa e Palma (2010) buscou analisar a produção científica na base de dados Anpad entre 1997 e 2009. Uma de suas conclusões é que apesar dos estudos não serem recentes, permanece a dificuldade na definição da inovação, tendo em vista a amplitude deste conceito. Pode-se colocar em evidência ainda que predominan os trabalhos de base empírica e que a tendência da gestão da inovação é torna-se cada vez mais estratégica para o desenvolvimento sustentável e a competitividade das organizações.

Já o trabalho de Ropelato, Silveira e Machado (2010) revelou os autores mais utilizados como base para inovação, sendo eles: Michael Porter, Keith Pavitt e Joseph Alois Schumpeter. Os autores analisaram em sua pesquisa uma amostra de 550 artigos da área de Administração, oriundos de revistas especializadas nacionais recomendadas e eventos brasileiros que incluíram inovação como tema nos anos de 2006 a 2009.

A pesquisa de Freitas e Muylder (2010) realizada nas edições do Enanpad compreendendo o período de 2005 a 2009 revela que a maioria dos artigos encontrados com os temas "empresas de base tecnológica" e "inovação" está presente nas Divisões Acadêmicas Gestão, Ciência, Tecnologia e Inovação (GCT) e Estratégias em Organizações (ESO). Logo, estas divisões acadêmicas são as que mais contribuem para os estudos acerca dos temas: inovação e empresa de base tecnológica.

Em face do exposto, observou-se nos trabalhos supracitados a relevância da contribuição de Schumpeter nos estudos relacionados ao empreendedorismo e inovação, bem como o tratamento isolado dos temas, empreendedorismo, inovação e incubadoras de base tecnológica. Deste modo, a presente pesquisa objetiva estender tais estudos, buscando aprofundar o conhecimento sobre a realidade da produção científica de forma integrada 
acerca do empreendedorismo inovador a partir das incubadoras de base tecnológica.

\section{Metodologia}

Esta seção está dividida em três subseções: enquadramento metodológico; bibliometria; e, etapas da pesquisa.

\subsection{Enquadramento metodológico}

A presente pesquisa classifica-se como descritiva em relação a natureza do objetivo de investigar a produção científica sobre o empreendedorismo inovador gerado pelas incubadoras de base tecnológica até o exercício de 2013. Andrade (2005, p.124) cita que nas pesquisas descritivas "os fatos são observados, registrados, analisados, classificados e interpretados, sem que o pesquisador interfira neles", ou seja, se descreve o comportamento dos fenômenos, identificando e obtendo informações sobre as características de um determinado problema ou questão (COLLIS; HUSSEY, 2005, p. 24).

Com o intuito de alcançar o objetivo proposto, optou-se como estratégia para a coleta, refinamento e análise dos dados, a bibliometria. MaciasChapula (1998, p. 134) cita que a bibliometria "é o estudo dos aspectos quantitativos da produção, disseminação e uso da informação registrada" e tem como princípio, segundo Santos (2003, p.29), "analisar a atividade científica ou técnica através de estudos quantitativos das produções".

Logo, a abordagem utilizada será quantitativa, pois se pretende identificar características da produção científica utilizando-se de meios estatísticos para tabulação dos dados e apresentação dos resultados (RICHARDSON, 1999, p. 7089). O horizonte de tempo é longitudinal, pois não se estabeleceu para realização da pesquisa um corte temporal inicial. Já em relação ao corte temporal final, este se deu a partir da finalização da coleta de dados, correspondente ao ano de 2013.

Trata-se de uma pesquisa bibliográfica, ou seja, a partir de bibliografias já publicadas no meio científico, deste modo a fonte de coleta de dados utilizada é de natureza secundária, que, conforme Richardson (1999, p.254) "intervêm entre a fonte e o acontecimento". Os dados foram coletados em bases de dados nacionais e internacionais (periódicos, eventos, dissertações e teses).

\subsection{Bibliometria: aspectos teóricos}

A bibliometria surgiu nos anos 1960, cunhada com esse nome por Pritchard (1969). Possui um caráter quantitativista, que orientou a formulação de leis matemáticas com o objetivo de mensurar a produção científica. Assim, segundo seu mentor (PRITCHARD, 1969, p. 348-349) a bibliometria significa: "todos os estudos que tentam quantificar os processos de comunicação escrita".

Para Braga (1973, p.10), a bibliometria representa um conjunto de leis destinadas ao "tratamento quantitativo das propriedades e do comportamento da informação registrada".

Em linhas gerais, pode-se compreender que a bibliometria analisa a atividade científica ou técnica pela abordagem quantitativa das publicações, construindo indicadores que permitam descrever e analisar as principais características do conjunto de produções sobre determinado tema, bem como sua evolução.

Destacam-se na contribuição da área em relação à criação de leis específicas para a análise da produção científica, três autores, que dão nome às principais leis que regem a bibliometria (GUEDES; BORSHIVER, 2005, p. 3-7):

Bradford: conexo à dispersão da literatura periódica científica, permite: "estimar o grau de relevância de periódicos 
em dada área do conhecimento, que os periódicos que produzem o maior número de artigos sobre dado assunto formam um núcleo de periódicos, supostamente de maior qualidade ou relevância para aquela área";

Lotka, associada à produtividade de autores, considera que: "alguns pesquisadores, supostamente de maior prestígio em uma determinada área do conhecimento, produzem muito e muitos pesquisadores, supostamente de menor prestígio, produzem pouco";

Zipf, estas permitem: "estimar as frequiências de ocorrência das palavras de um determinado texto científico e tecnológico e a região de concentração de termos de indexação, ou palavras-chave $[\ldots] "$.

Este estudo enquadra-se em maior parte nas Leis de Zipf que tem como intuito analisar a freqüência com que o tema é tratado e uma possível concentração de estudos científicos; e Lotka visando ainda de forma complementar analisar a produtividade de autores.

\subsection{Etapas da pesquisa}

Faz-se a priori a apresentação dos periódicos / anais de eventos e bancos de teses utilizados nesta pesquisa:

(i) EBSCO - Online Research Databases, é uma base de dados acadêmica para pesquisas online, possui âmbito internacional e seu acesso é realizado via assinaturas. É considerada umas das bases mais completas na área de negócios do mundo, oferece coleção de conteúdos bibliográficos com textos completos. Como parte da cobertura abrangente oferecida por esta base de dados, também estão incluídos os índices e resumos dos periódicos científicos acadêmicos mais importantes desde 1886, além das referências de mais de 1.200 periódicos científicos.

(ii) CAPES - Coordenação de Aperfeiçoamento de Pessoal de Nível Superior, possui um banco de dissertações e teses defendidas a partir de 1987. De âmbito nacional, seu acesso é realizado via assinaturas. As informações são fornecidas diretamente à Capes pelos programas de pós-graduação, que se responsabilizam pela veracidade dos dados.

(iii) DOMÍNIO PÚBLICO é um portal nacional que coloca à disposição de todos os usuários da rede mundial de computadores - Internet - uma biblioteca virtual. Foi lançada em novembro de 2004 e seu principal objetivo é o de promover o amplo acesso às obras literárias, artísticas e científicas.Seu acesso é realizado de forma livre e gratuita.

(iv) ANPAD - Associação Nacional de Pós-Graduação e Pesquisa em Administração desenvolve trabalhos na promoção do ensino, da pesquisa e na produção de conhecimento dentro do campo das ciências administrativas, contábeis e afins no Brasil. Promove anualmente vários eventos acadêmicos, os quais são publicados desde 1997. Seu acesso se dá por meio de assinatura.

(v) ANPROTEC

Associação Nacional de

Entidades Promotoras de Empreendimentos Inovadores atua na promoção do empreendedorismo inovador por meio do apoio ao Movimento Nacional de Parques Tecnológicos e 
Incubadoras de Empresas. De âmbito nacional, seu acesso é por meio de assinatura.

As bases de dados citadas anteriormente possuem estudos em diferentes formatos, deste modo, foram selecionados artigos completos contidos na base de dados Ebsco; dissertações e teses das bases nacionais Capes e Domínio Público, bem como artigos apresentados em eventos das bases da Anpad e Anprotec. Cabe salientar que o acesso às bases da Anprotec se deu relativamente aos anos 1999-2013, exceto o ano de 2003. No que se refere à base de dissertações e teses da Capes, sua análise ficou restrita até 2011, pois o portal tornou-se indisponível para o término da coleta de dados. Para o restante da busca não se estabeleceu um período específico, pois o intuito foi verificar a maior incidência em uma linha temporal das publicações até o mês de dezembro do presente ano, 2013. Na Figura 1 estão apresentadas as etapas do processo genérico utilizado para seleção dos trabalhos:

Figura 1: Fluxograma do processo genérico de busca de referências bibliográficas

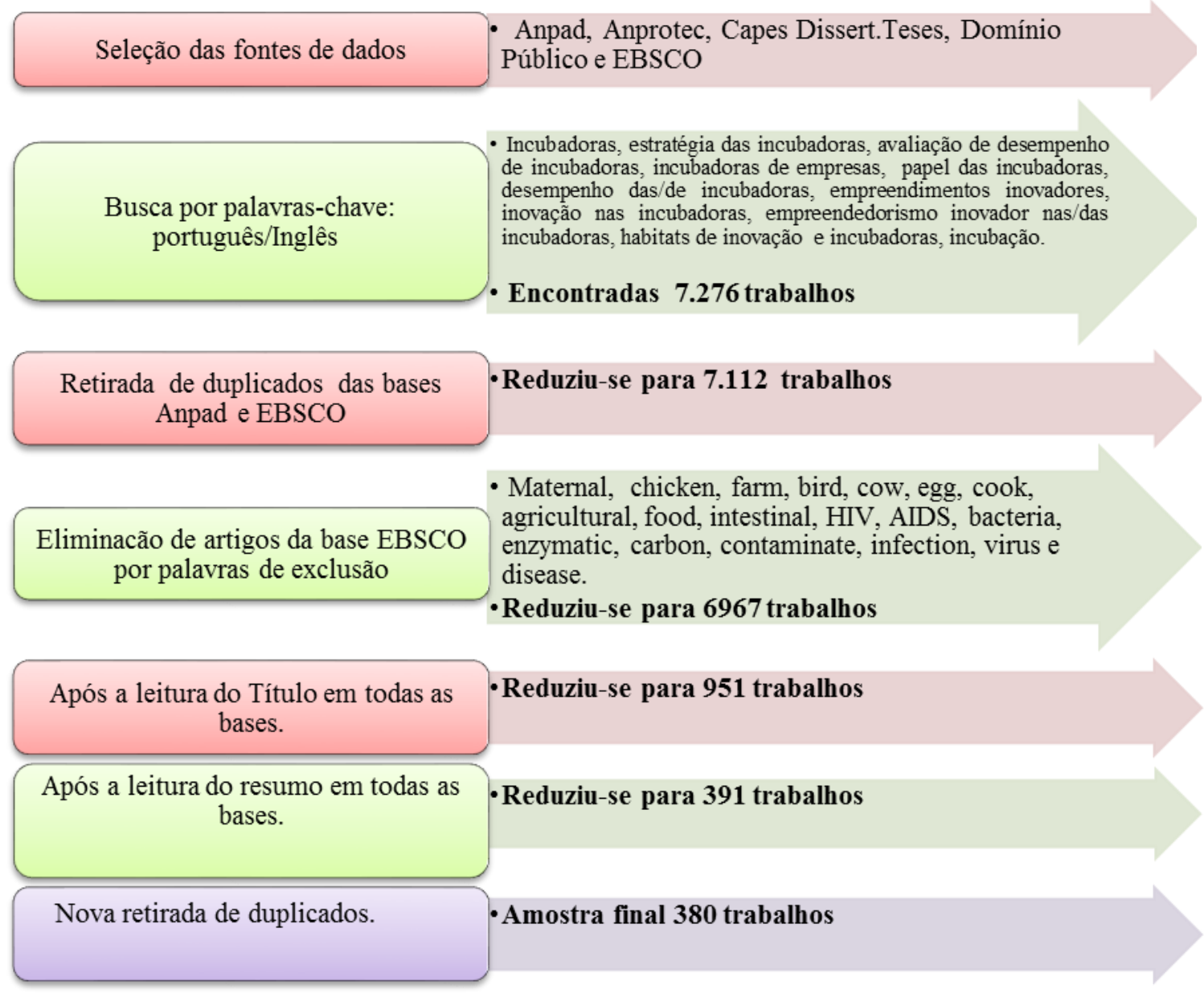

Fonte: Fonte: os autores, 2013.

Seguindo o fluxo da Figura1, a primeira etapa do processo, a de busca de artigos por meio das palavras-chave (vide
Quadro 1), resultou em 7.276 trabalhos encontrados. 
Empreendedorismo inovador gerado pelas incubadoras de base tecnológica: Mapeamento da produção científica até 2013

Quadro 1: palavras-chave utilizadas para a busca

\begin{tabular}{|l|l|}
\hline Português & Inglês \\
\hline Incubadora & Incubators \\
estratégia das incubadoras & Incubator strategy \\
avaliação de desempenho de incubadoras & performance evaluation of incubators \\
incubadoras de empresas & business incubators \\
papel das incubadoras & role of incubators \\
desempenho das incubadoras & performance of incubators \\
incubadoras e empreendimentos inovadores & enterprises incubators and innovators \\
inovação em incubadoras & innovation in incubators \\
incubadoras e processo inovador & incubators and innovation process \\
empreendedorismo inovador e/nas incubadoras & innovative entrepreneurship incubators \\
habitat de inovação e incubadoras & habitat for innovation and incubators \\
Incubação & Incubation \\
\hline
\end{tabular}

Fonte: os autores, 2013.

Especificamente na base Ebsco, utilizou-se uma ferramenta de gerenciamento bibliográfico, que auxiliou na retirada de artigos duplicados. Na base Anpad, a pesquisa foi realizada de forma manual, também foram identificadas duplicações, que assim como na Ebsco, foram eliminadas já nesta etapa. Deste modo, o total de trabalhos reduziu para a 7.112. Por conseguinte, também com o auxílio da ferramenta de gerenciamento, foram retiradas da base Ebsco artigos relacionados às palavras de exclusão, citadas na Figura 1, obtendo-se assim, 6.967 trabalhos.

A próxima etapa do processo consistiu em fazer a leitura dos 6.967 títulos, para excluir trabalhos que não estavam alinhados ao tema da pesquisa, ou seja, que se não tratavam da estratégia e desempenho das incubadoras de base tecnológica no processo de empreendedorismo inovador, chegou-se assim, a 951 trabalhos. A partir destes, foram lidos os resumos e também se eliminou os trabalhos não alinhados ao tema de pesquisa, obtendo como resultado 391 trabalhos.

$\mathrm{Na}$ última fase, que foi a de junção das bases, foram novamente revistas as possíveis duplicações. Nos casos onde houve repetições nas bases Capes e Domínio Público, permaneceram os trabalhos da base Capes. Já quanto aos artigos duplicados encontrados nos eventos Anpad e Anprotec optou-se por descartar os trabalhos da base Anprotec.

Tabela 1: busca e eliminação de referências bibliográficas

\begin{tabular}{|c|c|c|c|c|c|c|c|c|}
\hline \multicolumn{9}{|c|}{ Análise de produtos } \\
\hline & & \begin{tabular}{|c|} 
Total \\
encontrado via \\
palavras-chave \\
\end{tabular} & $\begin{array}{l}\text { Eliminação } \\
\text { duplicados }\end{array}$ & $\begin{array}{c}\text { Eliminação } \\
\text { por } \\
\text { palavras de } \\
\text { exclusão } \\
\end{array}$ & \begin{tabular}{|c|} 
Eliminação \\
após \\
leitura do \\
título \\
\end{tabular} & \begin{tabular}{|c|} 
Eliminação \\
após \\
leitura do \\
resumo \\
\end{tabular} & $\begin{array}{c}\text { Eliminação } \\
\text { duplicados na } \\
\text { junção de bases }\end{array}$ & $\begin{array}{c}\text { Amostra final } \\
\text { resultante por } \\
\text { base }\end{array}$ \\
\hline Bases de dados & EBSCO & 922 & 144 & 145 & 427 & 81 & 5 & 120 \\
\hline \multirow{2}{*}{$\begin{array}{c}\text { Dissertações e } \\
\text { teses }\end{array}$} & Domínio público & 20 & - & - & 8 & 2 & 0 & 10 \\
\hline & CAPES & 5690 & - & - & 5567 & 24 & 5 & 94 \\
\hline \multirow{4}{*}{ Eventos } & Anpad & 79 & 20 & - & 14 & 7 & 0 & 38 \\
\hline & Anprotec & 565 & - & - & - & 446 & 1 & 118 \\
\hline & $\begin{array}{c}\text { Total geral por } \\
\text { passo }\end{array}$ & 7276 & 164 & 145 & 6016 & 560 & 11 & 380 \\
\hline & $\begin{array}{l}\text { Total geral } \\
\text { eliminado }\end{array}$ & 6896 & & & & & & \\
\hline
\end{tabular}

Revista de Negócios, ISSN 1980-4431, Blumenau, Brasil, v. 19, n. 2, p. 86-108, Abril/Junho de 2014. 
Fonte: os autores, 2013.

O resultado final após a aplicação de todos os procedimentos da bibliometria, conforme Tabela 1, gerou uma amostra de 380 trabalhos. A partir da identificação desta amostra realizaram-se as análises apresentadas na quarta seção.

\section{Resultados}

Para melhor disposição, os resultados gerados foram organizados na seguinte ordem:

i) Autores mais prolíficos
A identificação de autores que mais publicam se faz importante para quem se dedica aos estudos bibliométricos, pois possibilita visualizar os novos pesquisadores do tema e aqueles que se destacam. No estudo, foram encontrados 630 autores diferentes. Entretanto, optouse por relacionar apenas os que obtiveram três ou mais publicações. Os dados abaixo evidenciam a participação não só de professores, mas também de pessoas físicas ligadas a instituições não universitárias.

Tabela 2: Autores mais prolíficos

\begin{tabular}{|c|c|c|c|}
\hline Autores & $\begin{array}{l}\text { Frequïência } \\
\text { Publicações }\end{array}$ & Instituição & UF \\
\hline Afonso Augusto Teixeira de Freitas de Carvalho & 05 & Universidade Federal de Viçosa & MG \\
\hline David N. Allen & 5 & Ohio University & EUA \\
\hline Fabiano Maury Raupp & 5 & Universidade do Estado de Santa Catarina (UDESC) & $\mathrm{SC}$ \\
\hline Gabriela Gonçalves Silveira Fiates & 5 & $\begin{array}{l}\text { Universidade do Sul de Santa Catarina/ Universidade } \\
\text { Federal de Santa Catarina }\end{array}$ & $\mathrm{SC}$ \\
\hline Guilherme Silveira Martins & 4 & Fundação Getúlio Vargas (FGV) & SP \\
\hline Ilse Maria Beuren & 4 & Universidade Regional de Blumenau (FURB) & $\mathrm{SC}$ \\
\hline Alessandra Vasconcelos Gallon & 3 & Universidade Federal do Ceará (UFC) & $\mathrm{CE}$ \\
\hline Alexandre Takeshi Ueno & 3 & Universidade Federal de Santa Catarina (UFSC) & $\mathrm{SC}$ \\
\hline Alisson Eduardo Maehler & 3 & Universidade Federal de Pelotas & RS \\
\hline Aruna Chandra & 3 & Indiana State University & \\
\hline Cristina Martins & 3 & $\begin{array}{l}\text { Universidade do Sul de Santa Catarina/ Universidade } \\
\text { Federal de Santa Catarina (UFSC) }\end{array}$ & $\mathrm{SC}$ \\
\hline Edison Afonso Maletz & 3 & Associação do Polo de Informática de Caxias do Sul & RS \\
\hline Ednalva Fernandes Costa de Morais & 3 & Universidade de Brasília (UNB) & $\mathrm{DF}$ \\
\hline Henry Etzkowitz & 3 & Newcastle University Business School & UK \\
\hline José Carlos Assis Dornelas & 3 & Fundação de Instituição de Administração (FIA)/USP & SP \\
\hline $\begin{array}{l}\text { Roberto Spolidoro } \\
\text { Ronaldo Sales Abranches }\end{array}$ & 3 & $\begin{array}{l}\text { NEOLOG Consultores Ltda } \\
\text { Faculdade de Ciências Sociais Aplicadas do Sul de } \\
\text { Minas ( FACESM) }\end{array}$ & $\mathrm{BR}$ \\
\hline Tony Chierighini & 3 & CELTA/Fundação CERTI & $\mathrm{SC}$ \\
\hline Wescley Silva Xavier & 3 & Universidade Federal de Minas Gerais (UFMG) & MG \\
\hline
\end{tabular}

Fonte: os autores, 2013.

Destaca-se nessa análise, que embora estejam relacionados apenas os autores mais prolíficos, a freqüência de publicação de cada autor não é significativa, variando de três a cinco artigos.

ii) Orientadores de dissertações/teses sobre o tema

Assim como há grande importância em saber quem são os autores mais prolíficos, não menos relevante se faz saber quem, e com que frequiência são os orientadores, responsáveis pelo acompanhamento das dissertações e teses na temática tratada, aqui representadas pelas bases Capes e Domínio Público. Assim, observa-se que a maior freqüência agrupada é representada por diferentes orientadores, estes com apenas uma orientação. Os nomes citados no Gráfico 2 
Empreendedorismo inovador gerado pelas incubadoras de base tecnológica: Mapeamento da produção científica até 2013

foram os que realizaram duas ou mais

área.

Gráfico 2: Número de publicações de orientados sobre o tema

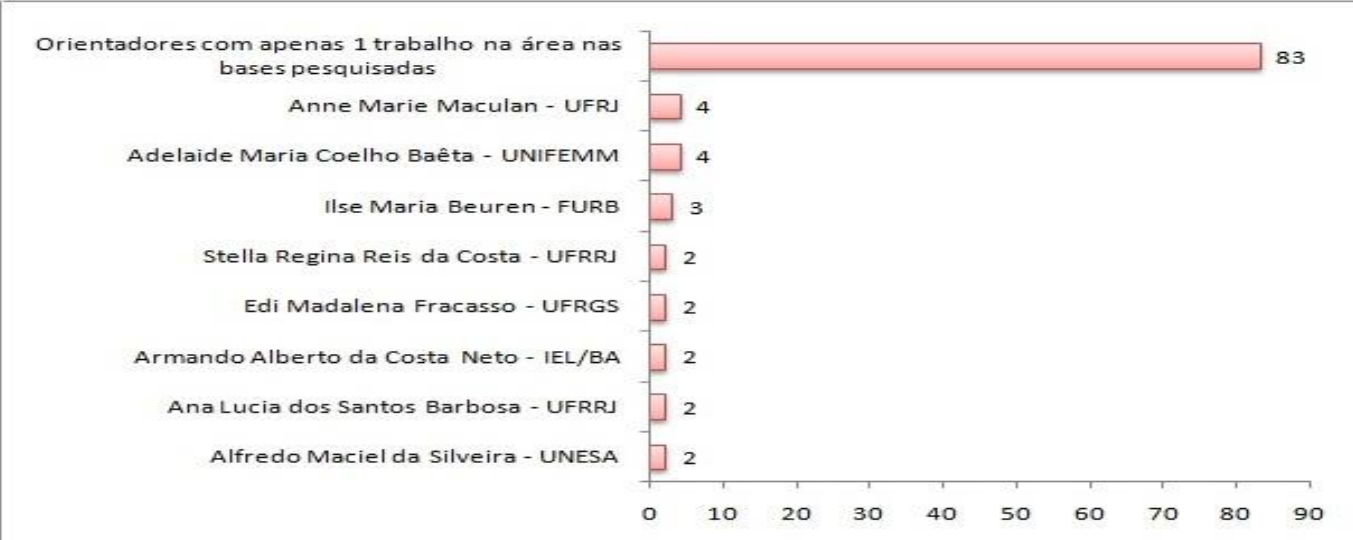

Fonte: os autores, 2013.

$\mathrm{Na}$ análise dos orientadores, chama a atenção o fato de que as duas professoras que mais orientaram não figuram entre os autores que mais publicaram nas bases estudadas. Aliás, destaca-se que apenas um dos orientadores, Prof ${ }^{a}$ Ilse Maria Beuren, figura em ambas as listas.

iii) Análise de redes sociais de colaboração

As redes de pesquisa impulsionam a criação do conhecimento e o processo de inovação resultantes do intercâmbio de informações e, sobretudo, da junção de competências de grupos que unem esforços na busca de metas comuns. Nesta perspectiva, a Figura 2 demonstra a análise de redes sociais de colaboração realizada sobre a seleção dos autores mais prolíficos desta pesquisa, os quais possuíam quatro ou mais publicações.

Figura 2: Rede social de colaboração entre os autores com quatro ou mais publicações

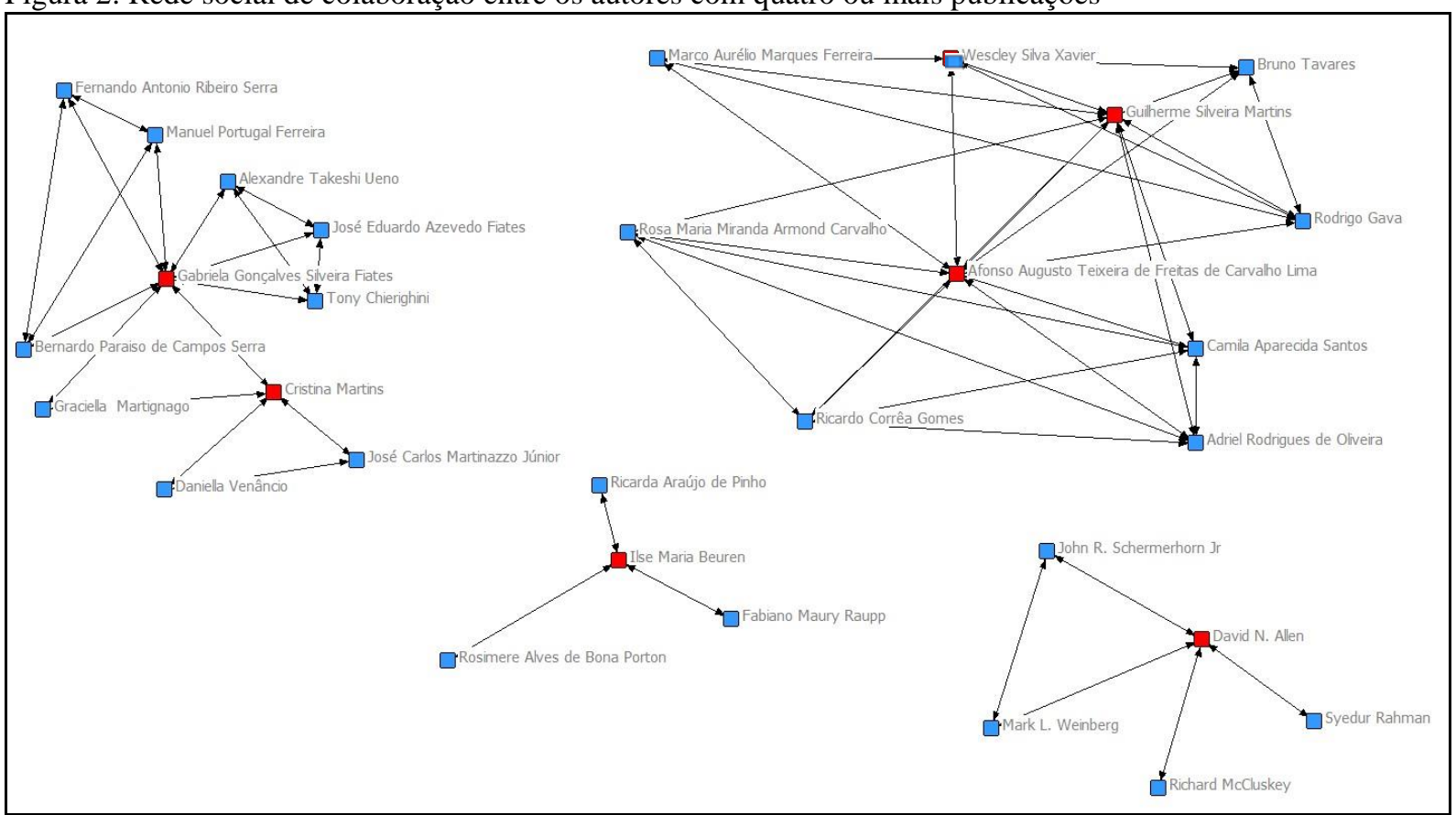

Fonte: elaboração própria com dados da pesquisa, 2013. 
Observa-se a ocorrência de laços fortes e laços fracos na rede social de cooperação entre autores. Os laços fortes são os que se caracterizam pela conexão direta dos atores em uma rede (GRANOVETTER, 1973), e estão representados na Figura 2 por nós circulares de cor vermelha, destacando-se os autores: Gabriela Gonçalves Silveira Fiates, Cristina Martins, David N. Allen, Ilse Maria Beuren, Afonso Augusto Teixeira de Freitas de Carvalho Lima e Guilherme Silveira Martins. Os dois últimos pesquisadores destacam-se por serem os atores principais da rede de cooperação de maior envolvimento ligando dez pesquisadores, e possuindo no mínimo um relacionamento com cada um dos outros nove autores da sua rede. Burt (1992) destaca que, quando o contato é feito por pessoas que já se conhecem, como no caso dos laços de cooperação fortes, as informações a serem compartilhadas tendem a ser as mesmas, com baixa tendência para mudança.

Os laços fracos consistem em contatos indiretos formados por meio de pontes, fornecendo diferentes fontes de informação (GRANOVETTER, 1973). Assim, no caso das redes de cooperação entre autores, os laços fracos consistem nos laços indiretos, fornecidos por meio da publicação com um autor que publica com outros autores. Os laços fracos observados na Figura 2 consistem nos laços fornecidos pelas autoras Gabriela Gonçalves Silveira Fiates com Cristina Martins e Afonso Augusto Teixeira de Freitas de Carvalho Lima com Guilherme Silveira Martins. Estes autores tornam-se centrais em suas redes (nó circular vermelho), visto que, por meio deles, pode ocorrer o fluxo de informações entre redes que, sem eles, seriam isoladas.

Portanto, pode-se perceber que os autores mais prolíficos Gabriela Gonçalves Silveira Fiates e Afonso Augusto Teixeira de Freitas de Carvalho Lima possuem além do maior número de relações, o melhor capital social da rede apresentada, visto que encontram em virtude de suas conexões e posição na estrutura social, maiores facilidades de acesso à informação, o que segundo Burt (1992), fornece uma vantagem competitiva em relação ao indivíduo que não realiza a conexão entre as diferentes redes.

iv) Evolução temporal

De 1968 a 2013, o Gráfico 3 apresenta a evolução temporal dos trabalhos selecionados em todas as bases sobre o tema aqui tratado,vale ressaltar que o percentual colocado é em relação ao total da amostra (380 trabalhos). 


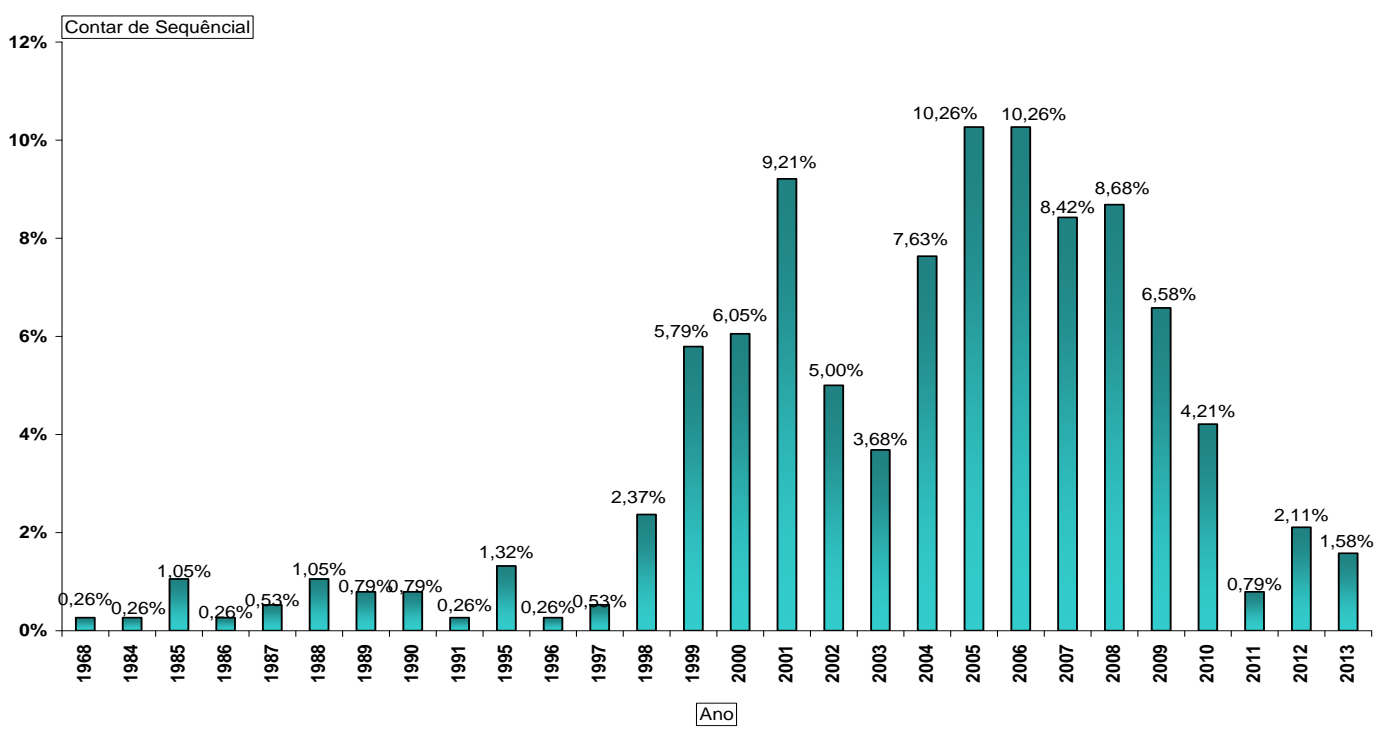

Fonte: os autores, 2013.

Observa-se que a pesquisa relacionada ao tema vem evoluindo constantemente ao longo dos anos com maior enfoque a partir do ano de 1998, atingindo o pico nos anos de 2005 e 2006, que representaram o período mais produtivo em termos de publicações. Um respaldo para o aumento representativo de publicações a partir desta evolução está ligado ao aumento do número de incubadoras, conforme demonstrado no Panorama Anprotec (2006), onde se destacam respectivamente os anos de 2005 e 2006, com 339 e 377 incubadoras em operação no Brasil. Adicionalmente, é relevante revelar que segundo dados da Anprotec (2006) 70\% dos negócios gerados no país pelas empresas são de base tecnológica.

v) Evolução ano-a-ano Anpad x Anprotec

Para efetuar esta análise, cruzaramse os dados referentes aos anos de publicações das bases Anpad e Anprotec, pautando-se no fato de ambas as publicações serem de eventos.

Gráfico 4: Anpad x Anprotec ano-a-ano

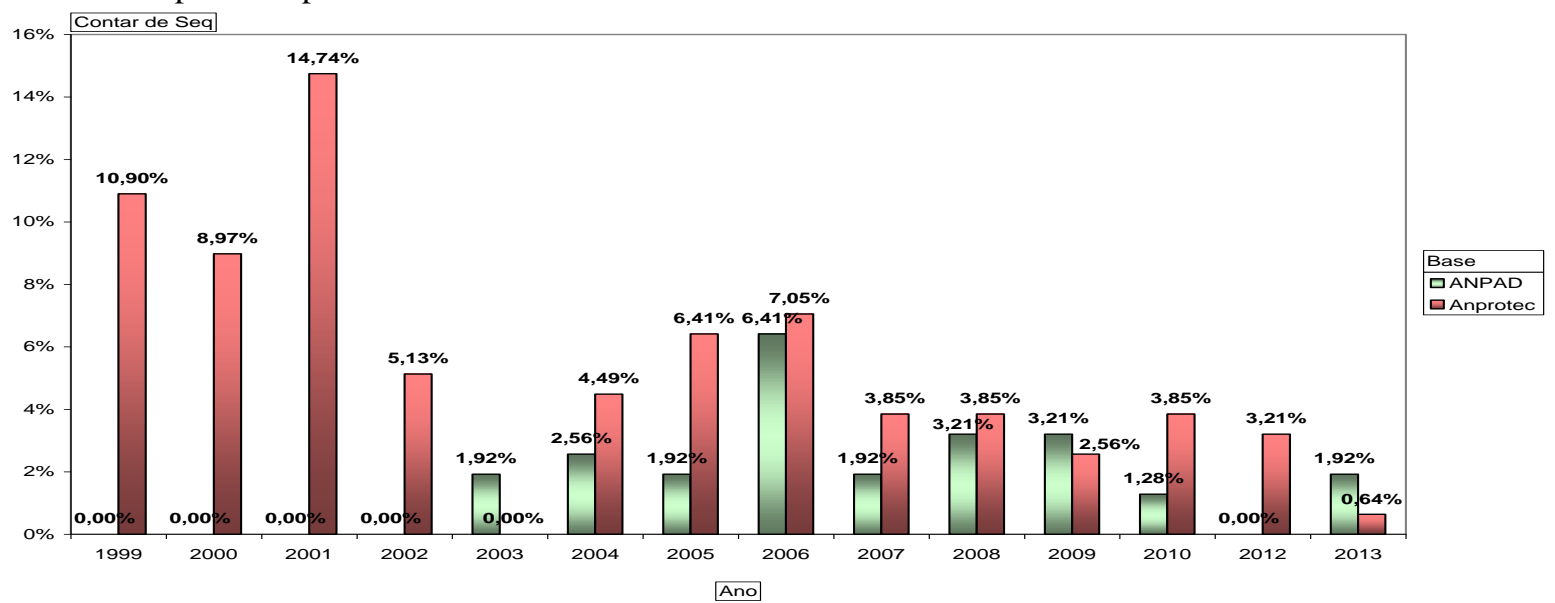

Fonte: os autores, 2013.

Nas comparações ano-a-ano cumpre-se salientar a impossibilidade de acesso a base do ano de 2003 da Anprotec.
Tal fato se deve pelo não acesso aos documentos na sua íntegra. $\mathrm{O}$ gráfico demonstra claramente no percurso, a 
grande vantagem da Anprotec sobre a Anpad, excetuando-se os anos de 2009 e 2013.

Esta discrepância significativa deve-se, sobretudo, a diferença de perfis dos eventos. Anpad é a Associação Nacional de Pós-graduação e Pesquisa em Administração, dessa forma a Anpad congrega vários eventos de cunho científico e com focos diversos, cada qual abordando áreas de conhecimento específicas. Já a Anprotec é a associação que representa os interesses das incubadoras de empresas, parques tecnológicos e empreendimentos inovadores no Brasil, tendo como foco um evento anual, para compartilhamento das experiências vivenciadas em empreendimentos práticos, embora pontualmente haja apresentações de trabalhos de cunho científico.

vi) Publicações eventos - Anpad

Com o intuito de propiciar a professores, pesquisadores e estudantes a possibilidade de intercâmbio de informações, a Anpad realiza anualmente diversos eventos acadêmicos, são eles:

Quadro 2: Eventos acadêmicos Anpad e seus segmentos

\begin{tabular}{ll}
\hline Evento & Segmento de estudo em Administração \\
\hline ENANPAD & Todas as divisões acadêmicas contempladas no Anpad \\
EMA & Divisão de Estudos em Marketing \\
3Es & Divisão Acadêmica de Estudos em Estratégia \\
EnEO & Divisão de Estudos Organizacionais \\
Simpósio & Gestão da Inovação Tecnológica \\
EnAPG & Divisões acadêmicas de Políticas Públicas e Gestão Pública e Governança \\
EnGPR & Divisão Acadêmica de Gestão de Pessoas e Relações de Trabalho \\
EnADI & desenvolvimento da área de estudos em Administração de Sistemas de Informação \\
EnEPQ & Espaço de discussão de temas relevantes para o momento no âmbito de Administração \\
\hline
\end{tabular}

Fonte: os autores, 2013.

Neste sentido, o Gráfico 5 ilustra os eventos promovidos pela ANPAD, nos quais foram encontrados trabalhos relacionados ao tema do estudo e as suas representatividades.

Gráfico 5: Anpad- eventos que mais publicaram na área

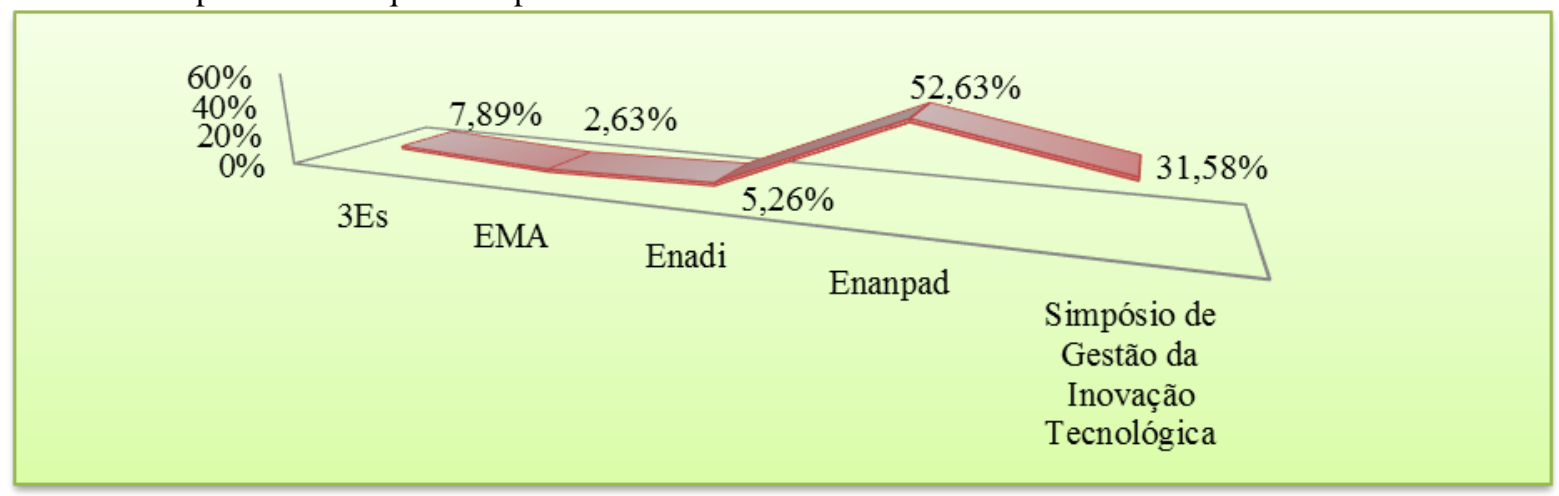

Fonte: Os autores, 2013.

Observa-se no Gráfico 5, o destaque dos eventos Enanpad e Simpósio de Gestão da Inovação Tecnológica, sendo que tal fato é facilmente justificado, pois o Enanpad é o evento que congrega todas as divisões contempladas na Anpad e o 
Empreendedorismo inovador gerado pelas incubadoras de base tecnológica: Mapeamento da produção científica até 2013

Simpósio trata justamente da área de gestão da inovação tecnológica.

Já o Gráfico 6 desdobra a

distribuição de artigos nos dois eventos considerados principais, conforme citado acima.

Gráfico 6: Temáticas Enanpad x Simpósio de Gestão da Inovação Tecnológica

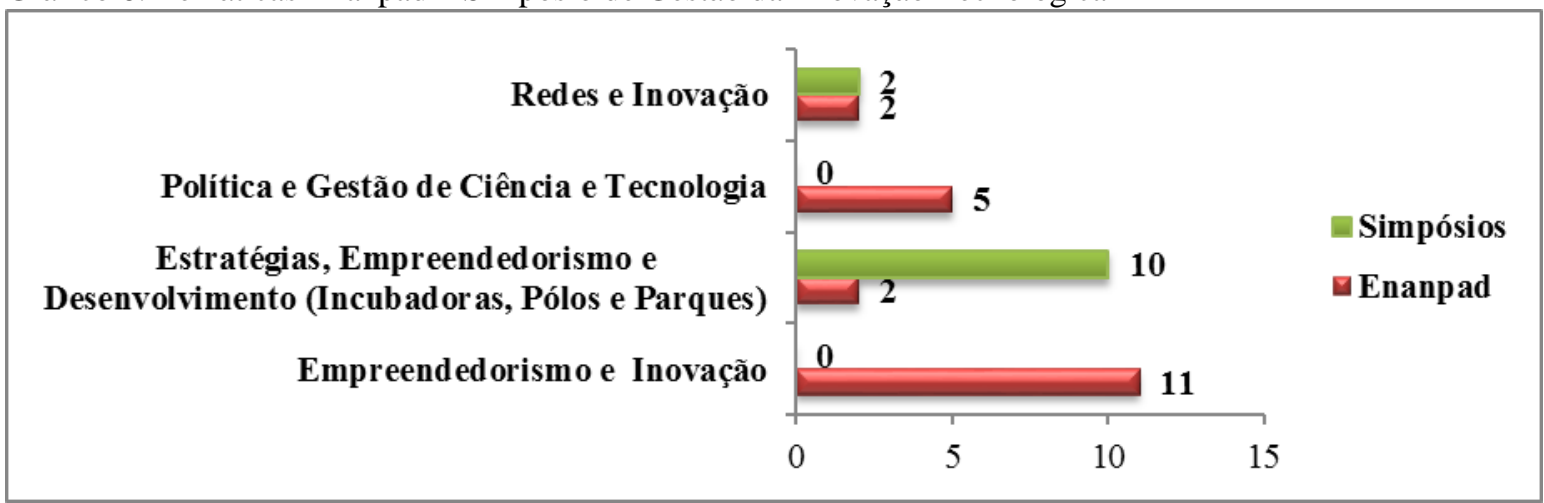

Fonte: os autores, 2013.

Observa-se que Empreendedorismo e Inovação, seguido de Estratégias, Empreendedorismo e Desenvolvimento (Incubadoras, Polos e Parques) foram as áreas temáticas que mais se destacaram, todavia um em cada evento, sendo o primeiro no Enanpad (11) e o segundo nos Simpósios (10) da Anpad. Temas como Redes e Inovação se demonstraram pouco explorados em ambos os eventos. Já em relação à Política e Gestão de Ciência e
Tecnologia, embora mais abordada no Enanpad, não obteve a partir dos critérios deste artigo representação nos Simpósios.

vii) Contagem de publicações por periódicos: base Ebsco

Dentre os artigos encontrados na base Ebsco cuja fonte foi possível identificar, optou-se por explicitar apenas os periódicos com três ou mais publicações.

Gráfico 7: Frequência em Periódicos base EBSCO

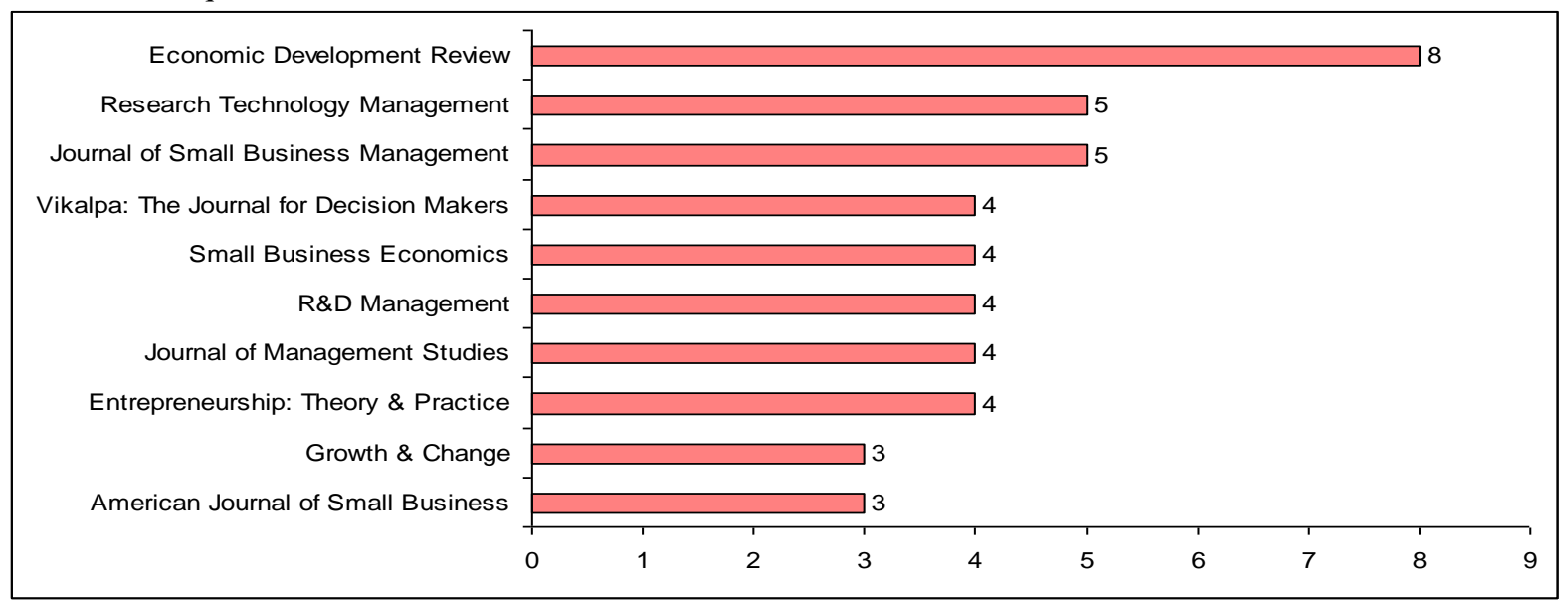

Fonte: os autores, 2013.

O periódico com maior número de publicações, conforme gráfico foi $\mathrm{o}$ Economic Development Review, destaca-se que sua linha editorial está ligada ao desenvolvimento econômico. Já o segundo colocado, Research Technology Management trabalha na linha das melhores práticas na gestão da inovação 
para os líderes de pesquisa, desenvolvimento e engenharia em todo o mundo. O terceiro periódico em destaque, Journal of small business management, tem como linha editorial a gestão de pequenos negócios e empreendedorismo.

viii) Níveis de publicações Capes $\mathrm{x}$ Domínio Público
Tanto a Capes quanto a base Domínio Público possuem semelhanças por serem repositórios de dissertações e teses. Estes trabalhos possuem níveis de classificação, tais como: Mestrado profissionalizante, Mestrado acadêmico e Doutorado. Observa-se que o valor mais representativo coube ao nível de mestrado acadêmico da base Capes, conforme se vê no Gráfico 8.

Gráfico 8: Nível das publicações base Capes versus Domínio Público (porcentagem).

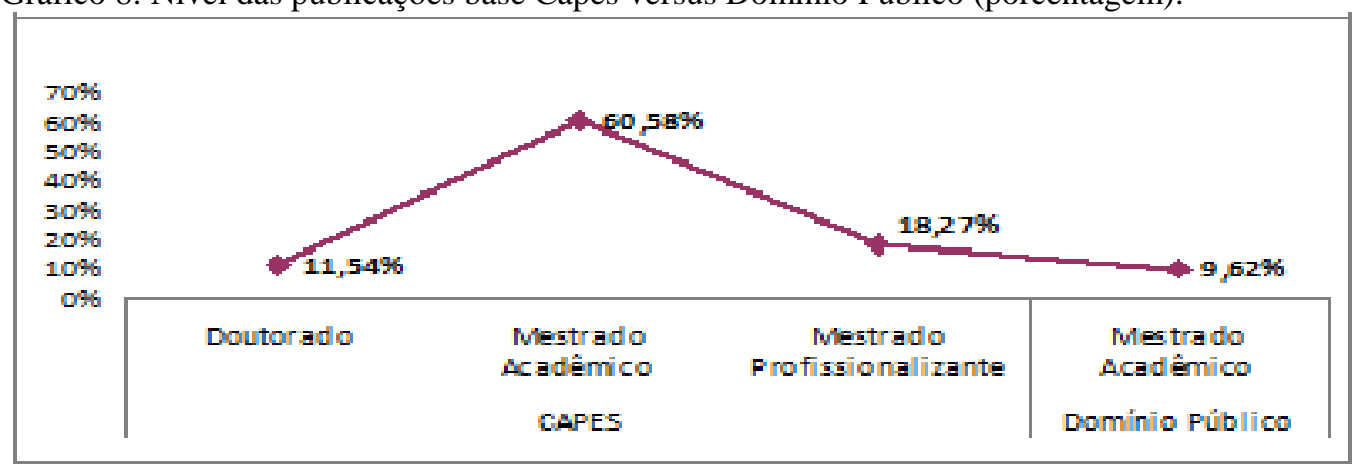

Fonte: os autores, 2013.

O resultado já era esperado, tendo em vista o número de cursos de mestrado acadêmico, que representa 72 cursos, versus 38 cursos de mestrado profissionalizante e 33 cursos de doutorados na área de administração, conforme dados da CAPES (2011). ix) Instituições que mais publicaram Foram identificadas instituições diferentes vinculadas aos 380 trabalhos. Dentre estas, optou-se por demonstrar as instituições com três ou mais publicações, bem como agrupar instituições de mesma nomenclatura, mas com localizações diferentes.

Tabela 3: Instituições que mais publicaram

\begin{tabular}{ll}
\hline Instituições identificadas & Número de publicações \\
Universidade Federal de Santa Catarina & 19 \\
Pontifícia Universidade Católica & 10 \\
Universidade Federal do Rio de Janeiro & 9 \\
Universidade Federal de Pernambuco & 7 \\
Fundação Getúlio Vargas & 7 \\
Universidade de São Paulo & 7 \\
Universidade Federal Fluminense & 6 \\
Universidade Federal de Santa Maria & 5 \\
Universidade Federal de Minas Gerais & 5 \\
Universidade Federal do Rio Grande do Sul & 5 \\
Centro Federal de Educação Tecnológica & 5 \\
Universidade Estadual de Maringá & 5 \\
Instituto Euvaldo Lodi & 4 \\
Unisinos-RS & 4 \\
Universidade de Brasília & 4
\end{tabular}

Revista de Negócios, ISSN 1980-4431, Blumenau, Brasil, v. 19, n. 2, p. 86-108, Abril/Junho de 2014. 
Empreendedorismo inovador gerado pelas incubadoras de base tecnológica: Mapeamento da produção científica até 2013

Universidade Federal da Bahia 4

Universidade Estadual de Londrina 4

Universidade Regional de Blumenau 4

Faculdades Integradas de Pedro Leopoldo 4

Universidade do Sul de Santa Catarina 5

University of Illinois 3

University of St. Gallen $\quad 3$

CDT-Brasília $\quad 3$

CELTA-SC

Indian Institute of Management 3

Pennsylvania State University 3

SEBRAE

3

Fonte: os autores, 2013.

Nota-se na Tabela 3 que a Universidade Federal de Santa Catarina tem um número relevante de trabalhos sobre o tema, ficando em primeiro lugar da lista. Tal resultado pode ser justificado, pois conforme dados da CERTI (2011), Fundação Centros de Referência em Tecnologias Inovadoras, criada a partir das atividades do Laboratório de Metrologia do Departamento de Engenharia Mecânica da UFSC, a atuação em Empreendedorismo Inovador deu-se no ano de 1986, com a criação da Incubadora Empresarial Tecnológica (hoje denominada CELTA), em Florianópolis, a pioneira do Brasil no gênero, juntamente com a incubadora de São Carlos (SP).

É possível ainda, verificar que dentre as instituições acadêmicas, visivelmente predominantes, a instituições empresariais, vêm ganhando destaque por também publicar sobre o tema.

\section{x) Análise de conteúdo}

$\mathrm{Na}$ Tabela 4, encontram-se de forma sumarizada os resultados da análise de conteúdo realizada sobre os objetivos dos 380 trabalhos selecionados como amostra final. Nos macro objetivos levantados, é possível perceber a predominância acerca do tema empreendedorismo inovador a partir das incubadoras. É destaque também em relação a frequiência deste, o grande número de trabalhos publicados em todas as três divisões aqui abordadas: dissertações e teses, artigos em eventos e periódicos.

Tabela 4: Análise de conteúdo

\begin{tabular}{|c|c|c|c|}
\hline Bases & $\begin{array}{l}\text { Frequência } \\
\text { por base }\end{array}$ & $\begin{array}{c}\text { Total por } \\
\text { objetivo }\end{array}$ & Tema /Abordagem \\
\hline Dissertações e teses & 66 & \multirow{3}{*}{224} & \multirow{3}{*}{$\begin{array}{l}\text { a) Relacionam as incubadoras ao desenvolvimento de } \\
\text { empreendedorismo/inovação e desenvolvimento local/regional. }\end{array}$} \\
\hline Artigos em eventos & 81 & & \\
\hline Artigos em Periódicos & 77 & & \\
\hline Dissertações e teses & 4 & \multirow{3}{*}{26} & \multirow{3}{*}{$\begin{array}{l}\text { b) Relacionam as incubadoras ao desenvolvimento de } \\
\text { empreendedorismo/inovação incluindo a dimensão competências, } \\
\text { transferência de conhecimento e aprendizagem. }\end{array}$} \\
\hline Artigos em eventos & 15 & & \\
\hline Artigos em Periódicos & 7 & & \\
\hline Dissertações e teses & 3 & \multirow{3}{*}{10} & \multirow{3}{*}{$\begin{array}{l}\text { c) Relacionam incubadoras com empreendedorismo/inovação e } \\
\text { desempenho. }\end{array}$} \\
\hline Artigos em eventos & 6 & & \\
\hline Artigos em Periódicos & 1 & & \\
\hline Dissertações e teses & 3 & \multirow{2}{*}{16} & \multirow{2}{*}{ d) Relacionam incubadoras a desempenho e avaliação de desempenho } \\
\hline Artigos em eventos & 7 & & \\
\hline
\end{tabular}

Revista de Negócios, ISSN 1980-4431, Blumenau, Brasil, v. 19, n. 2, p. 86-108, Abril/Junho de 2014. 


\begin{tabular}{|c|c|c|c|}
\hline Artigos em Periódicos & 6 & & \\
\hline Dissertações e teses & 11 & \multirow{3}{*}{40} & \multirow{3}{*}{$\begin{array}{l}\text { e) Tratam da gestão das incubadoras discutindo seus modelos de gestão, } \\
\text { internacionalização e representação social. }\end{array}$} \\
\hline Artigos em eventos & 23 & & \\
\hline Artigos em Periódicos & 6 & & \\
\hline Dissertações e teses & 14 & \multirow{3}{*}{54} & \multirow{3}{*}{$\begin{array}{l}\text { f) Relacionam incubadoras ao processo de aprendizagem e transferência } \\
\text { de conhecimento. }\end{array}$} \\
\hline Artigos em eventos & 18 & & \\
\hline Artigos em Periódicos & 22 & & \\
\hline Dissertações e teses & 3 & \multirow{3}{*}{10} & \multirow{3}{*}{ g) Relacionam incubadoras à sua gestão focando no Marketing. } \\
\hline Artigos em eventos & 5 & & \\
\hline Artigos em Periódicos & 2 & & \\
\hline \multicolumn{2}{|c|}{ Total Geral } & 380 & \\
\hline
\end{tabular}

Fonte: elaboração própria com dados da pesquisa, 2013.

Dentre as menores frequências da Tabela 4 apresentaram-se trabalhos que relacionam as incubadoras à gestão com foco em Marketing, bem como outro grupo que relaciona as incubadoras ao empreendedorismo inovador por meio de seu desempenho. $\mathrm{O}$ que permite inferir a descoberta de lacunas teóricas a cerca das temáticas. Sobretudo, cumpre ressaltar que a contribuição das incubadoras no desenvolvimento do processo de empreendedorismo inovador, foco subjacente desta pesquisa, fora apresentado exclusivamente em dois artigos publicados nos eventos Anprotec e Enanpad, respectivamente em 2012 e 2013 - Martins, Fiates (2012) e Martins, Venâncio e Martinazzo-Jr. (2013)- o que demonstra o quão recente e, inclusive incipiente são os estudos sobre o papel que as incubadoras de base tecnológica desempenham para o fenômeno.

Cumpre-se salientar que dos dez trabalhos sinalizados como mais aproximativos ao tema (c), o qual se tem maior interesse, quatro utilizaram metodologia de avaliação de desempenho Multicritério em Apoio à Decisão (MCDA), dois utilizaram o Balanced Score Card (BSC), um propôs um sistema de indicadores não atrelado à ferramentas de avaliação e, o restante não se conseguiu identificar durante a análise dos objetivos. Diante disso, torna-se oportuno através de estudos futuros contribuir para esta lacuna, pois as incubadoras são consideradas mecanismos que facilitam o desenvolvimento do empreendedorismo inovador (MARTINS, 2012).

Em tempo, confrontando estes resultados aos estudos anteriores, pode-se perceber a permanência das contribuições de Schumpeter acerca da temática, realçando a dificuldade explicitada para definição dos conceitos de empreendedorismo e inovação, característica estudada em alguns bibliométricos de forma isolada e que aqui se tentou unificá-los no conceito como empreendedorismo inovador, focando-o a partir de uma de suas grandes fontes, as incubadoras de base tecnológica.

\section{Considerações finais}

Face ao objetivo de investigar a produção científica sobre o empreendedorismo inovador gerado pelas incubadoras de base tecnológica até o exercício de 2013 analisaram-se 380 publicações, que coletadas a partir das bases Ebsco, Capes, Domínio Público, Anpad e Anprotec possibilitaram uma melhor compreensão acerca da temática.

Dentre as principais contribuições, percebeu-se a relação entre o crescimento do número de publicações e o aumento do número de incubadoras de base tecnológica no Brasil. Isso sugere que não só políticas de fomento foram aplicadas para impulsionar as incubadoras em busca de desenvolvimento para as MPEs e para a economia, mas que também a academia despertara interesse pelo assunto, muito 
Empreendedorismo inovador gerado pelas incubadoras de base tecnológica: Mapeamento da produção científica até 2013

embora tal interesse seja recente e considerado ainda pouco explorado.

Nesta seara, as instituições, não apenas representadas por Universidades, também demonstraram interesse pelo tema ao adentrar no rol de publicações. Mesmo que de forma tímida isso indica preocupações com a disseminação de conhecimentos, sobretudo a partir da prática, o que fora fortemente corroborado na pesquisa pela intensa produção apresentada pela Anprotec, a associação que cuida dos interesses das incubadoras, polos, parques e empreendimentos inovadores no Brasil.

No que tange à análise das redes de colaboração, onde se destacaram os autores Gabriela Gonçalves Silveira Fiates e Afonso Augusto Teixeira de Freitas de Carvalho Lima por possuírem o melhor capital social, percebeu-se que embora a academia tenha trabalhado em grupo, o compartilhamento do conhecimento considerado matéria-prima para inovação e fonte de vantagem competitiva ainda padece de maiores estímulos, já que as redes apresentadas em sua maioria não se conectam ou possuem apenas uma conexão com outro grupo como os autores supracitados, o que não favorece de forma suficiente a criação de novos conhecimentos e instigar a mudança.

Diante do exposto, considera-se como principal contribuição deste estudo a identificação de lacunas de pesquisa, que sugerem a construção de uma agenda futura para contemplar estudos que associem as incubadoras com à gestão de marketing e que, sobretudo aprofundem-se na avaliação da contribuição das incubadoras de base tecnológicas no desenvolvimento do processo de empreendedorismo inovador, pois nas bases analisadas foram encontrados apenas dois trabalhos ainda iniciantes vinculados à esta proposta.

Por fim, observa-se que a aplicação do estudo embora abrangente da perspectiva nacional e internacional possua limitantes, primeiro em relação ao não acesso dos dados de 2003 da base Anprotec e dos dados de 2012 e 2013 da Capes, o que traria uma análise mais completa. Segundo limitante se refere a algumas comparações que não foram aplicáveis pela escolha de bases de dados com finalidades e tipos de publicações diversificadas.

\section{Referências}

ALLEN, D. N.; R. MCCLUSKEY. Structure, policy, services, and performance in the business incubator industry. Entrepreneurship: Theory \& Practice v. 15, n.2, p. 61-77, 1990.

ANDRADE, M. M. Introdução à metodologia do trabalho científico. 7 . ed. São Paulo: Atlas, 2005.

ANPROTEC. Panorama Nacional Anprotec 2006. Disponível em: < http://www.anprotec.org.br/ArquivosDin/ Graficos_Evolucao_2006_Locus_pdf_59.p df>. Acesso em: 29 jun. 2011.

Bases de dados em Seminário Nacional de Parques Tecnológicos e Incubadoras de Empresas 9-11., Brasília: ANPROTEC, 1999-2010. CD-ROMs.

Anprotec e Sebrae constroem novo modelo de atuação para as incubadoras brasileiras. 2011. Disponível em: <http://www.anprotec.org.br/publicacao.ph p?idpublicacao=2212> Acesso em: $11 \mathrm{mar}$. 2012.

AERNOUDT, R. Incubators: Tool for Entrepreneurship? Small Business Economics. Sep2004, Vol. 23 Issue 2, p127-135. 9p.

BALDISSERA, I. Incubadora de Empresa: as Experiências no alto e médio Vale do Rio do Peixe. Videira: Ed. UNOESC/Campus Videira, 2001.

BARBIERI, J.C. (Org.) Organizações Inovadoras: estudos e casos brasileiros. Rio de Janeiro: FGV, 2003.158 p. 
BORBA, M. L.; HOELTGEBAUM, M.; SILVEIRA, A. A produção científica em empreendedorismo: análise do academy of management meeting: 1954-2005. RAM, REV. ADM. MACKENZIE, V. 12, N. 2, SÃO PAULO, SP, MAR./ABR. 2011.

BRAGA, G. Relações bibliométricas entre a frente de pesquisa (research front) $\mathrm{e}$ revisões da literatura: estudo aplicado à Ciência da Informação. Ciência da Informação, v. 2, n. 1, p.9-26, 1973.

BRASIL. Ministério da Ciência e Tecnologia. Manual para implantação de Incubadoras de Empresas. 2000. Disponível em: < http://www.incubaero.com.br/download/m anual_incubadoras.pdf $>$. Acesso em: 20 nov. 2011.

BRASIL. Portal Brasil. Mapa das micro e pequenas empresas. Disponível em: <http://www.brasil.gov.br/economia-eemprego/2012/02/o-mapa-das-micro-epequenas-empresas $>$. Acesso em: 03 mai. 2014.

BURT, R. Structural Holes: The Social Structure of Competition. Cambridge, MA: Havard University Press, 1992. Structural Holes and Good Ideas, v. 110, n. 2, set. 2004, p. 349-399.

CANTILHON, R. Essay on the nature of commerce. [S.1]: VirtualBooks, 1755. Disponível em: http://books.google.com.br/books?id=6007 AAAAcAAJ\&printsec $=$ frontcover \&hl=ptBR\&source $=g b s$ ge_summary_r\&cad $=0 \#$ $\mathrm{v}=$ onepage $\& \mathrm{q}=$ incertain $\& \mathrm{f}=$ false $>$. Acesso em: 16 jan. 2012.

CAPES. Banco de Teses. Disponível em: $<$

http://www1.capes.gov.br/bdteses/pavanca daassunto.asp>. Acesso em mai. 2011.

Reconhecidos. Disponível em: < http://conteudoweb.capes.gov.br/conteudo web/ProjetoRelacaoCursosServlet?acao $=p$ esquisarArea\&codigoGrandeArea $=600000$ 07\&descricaoGrandeArea $=$ CI\%CANCIAS
+SOCIAIS+APLICADAS+>. Acesso em: 29 jun. 2011.

\section{CERTI. A História da Fundação CERTI.}

Disponível em:

http://www.certi.org.br/pt/a-fundacaocerti/a-historia-da-fundacao-certihistorico.html>. Acesso em: 29 jun. 2011.

CHALELA, L.R. O empreendedorismo e a inovação em ambientes de incubação. 2008. 187 p. Dissertação (Mestrado em administração) - Universidade de Caxias do Sul. Caxias do Sul, 2008.

COLliS, J; HUSSEY,R. Pesquisa em administração: Um guia prático para alunos de graduação e pós-graduação. 2.ed. Porto Alegre: Bookman, 2005.

DOLABELA, F. Oficina do empreendedor: a metodologia de ensino que ajuda a transformar conhecimento em riqueza. São Paulo: Cultura Editores Associados, 1999.

DRUCKER, P. F. Inovação e Espírito Empreendedor: Práticas e princípios. Tradução de Carlos Malferrari. São Paulo: Cengage Learning, 2010.

FECOMÉRCIO. Federação do Comércio de Bens, Serviços e Turismo. Pequenas empresas precisam de cuidados especiais. 2011. Disponível em: < http://www.fecomercio.com.br/NoticiaArti go/Artigo/2673>. Acesso em: 20 nov. 2011.

FREITAS, M. M.; MUYLDER, C. F. Inovação e empresa de base tecnológica: Estudo bibliométrico. 2010. Disponível em:

<http://www.ead.fea.usp.br/semead/13sem ead/resultado/trabalhosPDF/259.pdf $>$.

Acesso em: 19 jun. 2011.

GRANOVETTER, M. The Strength of Weak Ties. American Journal of Sociology, v. 78, n. 6, 1973, p. 1360-1380.

GUEDES, V. L. S; BORSCHIVER, S. Bibliometria: uma ferramenta estatística para a gestão da informação e do conhecimento, em sistemas de informação, 
de comunicação e de avaliação científica e tecnológica. 2005. Disponível em: <http://dici.ibict.br/archive/00000508/01/V aniaLSGuedes.pdf > Acesso em: 18 jun. 2011.

KNEIPP, J. M; GOMES, C. M; ROSA, L. A. B; PALMA, L.P. Emergência Temática da inovação: Uma análise da produção científica Brasileira no período de 1997 a 2009. Disponível em: <http://www.ead.fea.usp.br/semead/13sem ead/resultado/trabalhosPDF/873.pdf $>$.

Acesso em: 19 jun. 2011.

MACIAS-CHAPULA, C.A. O papel da infometria e da cienciometria e sua perspectiva nacional e internacional. Ciência da Informação, Brasília, v.27, n.2, p. 134-140, maio/ago. 1998.

MARKATOU, M.; STOURNARAS, Y. Innovation for entrepreneurship: is new technology a driving mechanism for the creation of a firm? Journal of Global Business \& Technology, September 1, 2013

MARTINS, C., FIATES, G. G. S. Sistema de indicadores de desempenho das incubadoras no processo de desenvolvimento do empreendedorismo inovador In: SEMINÁRIO NACIONAL DE PARQUES TECNOLÓGICOS E INCUBADORAS DE EMPRESAS, 2012, Foz do Iguaçu - PR. Anais... Paraná: ANPROTEC, 2012.

MARTINS, C.; O papel das incubadoras de empresas do polo tecnológico de Florianópolis no desenvolvimento do processo de empreendedorismo inovador. 2013.269 f. Dissertação (Mestrado em Administração) Universidade do Sul de Santa Catarina, Florianópolis, 2013.

MARTINS, C., VENANCIO, D. M., MARTINAZZO JUNIOR, J. C. O Papel das Incubadoras de Empresas do Polo Tecnológico de Florianópolis no Desenvolvimento do Processo de Empreendedorismo Inovador. In:
ENCONTRO DA ANPAD - ENANPAD, 2013, Rio de Janeiro. Anais... Rio de Janeiro: ANPAD, 2013. p.1 - 16.

MCT. MINISTÉRIO DA CIÊNCIA E TECNOLOGIA. Manual para implantação de Incubadoras de Empresas. 2000. Disponível em: < http://www.incubaero.com.br/download/m anual_incubadoras.pdf >. Acesso em: 20 nov. 2011.

MUYLDER, C. F; ROCHA, A. M; GONÇALVES, C. M; SOUZA, R. B. Uma análise bibliométrica no evento ENANPAD 2007. Revista Gestão \& Tecnologia, Pedro Leopoldo, v.8, n.1, p.113, jan./jul.2008.

OLIVEIRA, C. L. S; MUYLDER, C. F. A Academia $\quad$ e $\quad$ o $\quad$ Termo "Empreendedorismo" um Estudo Bibliométrico ENANPAD 2007-2008. Disponível em: <http://www.ead.fea.usp.br/semead/12sem ead/resultado/trabalhosPDF/22.pdf>.

Acesso em: 19 jun. 2011.

PRITCHARD, A. Statistical bibliography or bibliometricas? Journal of Documentation, v. 25 , n. 4, p. 348-349. 1969.

RICHARDSON, R.J. Pesquisa Social: métodos e técnicas. 3. ed. São Paulo: Atlas, 1999. Cap. 5, p. 79-254.

ROPELATO, M; SILVEIRA, A; MACHADO, D. D. P. N. Inovação: análise da produção científica brasileira: 2006-2009. In: SIMPOI, 2010, São Paulo. Disponível em: <http://www.simpoi.fgvsp.br/arquivo/2010 /artigos/E2010_T00193_PCN08665.pdf>. Acesso em: 19 jun. 2011.

RUSHING, F. W. Entrepreneurship and education. In: KENT, C. A. Entrepreneurship Education: current developments. New York: Quorum Books, 1990. Cap.4, p. 41. Disponível em: <http://www.questia.com>. Acesso em 20 jun. 2011. 
SALAZAR, G. T.; OLIVEIRA, L. Competências empreendedoras: capacidades diferenciadoras e estratégias financeiras. In: CONGRESSO NACIONAL DE EMPREENDEDORISMO CONEMPRE, 1., 2003, Florianópolis. Anais... Florianópolis: CONEPRE, 2003.

SANTOS, R. N. M. Produção Científica: Por que medir? O que medir?. Revista Digital de Biblioteconomia e Ciência da Informação. Campinas, v.1, n.1, p22-30, jul./dez., 2003.

SARKAR, S. O empreendedor inovador: faça diferente e conquiste seu espaço no mercado. Rio de Janeiro: Elsevier, 2008.

SAY, J.B. Traité d'économie politique : Livre I (de la production des richesses). ed. Original de 1803.Disponível em < http://sbisrvntweb.uqac.ca/archivage/1386 8104t1.pdf >. Acesso em: 16 jan. 2012.

SCHUMPETER, J. A. The theory of economic development. Cambridge, MA: Harvard University Press, 1934.

SMITH, A. Inquérito sobre a natureza e as causas da riqueza das nações. V. 1. 2. ed. Original de 1776. Lisboa: Fundação Calouste Gulbenkian, 1987. 